\title{
Chemical Attraction of Gall Midge Pollinators (Cecidomyiidae: Cecidomyiinae) to Anthurium acutangulum (Araceae)
}

\author{
Florian $\mathrm{EtI}^{1} \cdot$ Wittko Francke $^{2} \cdot$ Jürg Schönenberger ${ }^{1} \cdot$ Stefan Dötterl $^{3}$ (1)
}

Received: 9 September 2021 / Revised: 20 January 2022 / Accepted: 26 January 2022 / Published online: 8 March 2022

(c) The Author(s) 2022

\begin{abstract}
Flowering plants often use chemical signals to attract their pollinators, and compounds that elicit attraction are known for several groups of pollinators. For other pollinators such as gall midges, however, compounds responsible for their attraction to flowers are largely unknown. Here, we describe the pollination biology of Anthurium acutangulum, a Neotropical aroid species found to be attractive to gall midges. We collected and analyzed its floral scent by dynamic headspace collections and gas chromatography coupled to mass spectrometry, and identified compounds responsible for pollinator attraction. The inflorescences were almost exclusively visited by gall midges (females; Cecidomyiidae: Cecidomyiinae) and released a strong scent reminiscent of freshly cut cucumber, mainly (5S,7S)-trans-conophthorin, (E2,Z6)-2,6-nonadienal, and cisconophthorin. Behavioral assays with the two most abundant compounds identified (E2,Z6)-2,6-nonadienal as being highly attractive to the female gall midge pollinators, whereas $(5 S, 7 S)$-trans-conophthorin was not attractive. Overall, we introduce a new specialized gall midge pollination system and identify the chemical mediating communication between the pollinators and their host plants.
\end{abstract}

Keywords Chemical communication $\cdot$ Cucumber aldehyde $\cdot$ Flower scent $\cdot$ Gall midge Pollination $\cdot$ Spiroacetals

\section{Introduction}

Many vertebrate and non-vertebrate pollinators are attracted to their host plants by, among other cues, floral scents (Raguso 2008). These volatile organic compounds are highly diverse, with more than 2000 components described so far (El-Sayed 2021; Knudsen et al. 2006). Attractive compounds are known for several groups of animal pollinators, such as mammals, bees, and beetles (Dötterl et al. 2012; Raguso 2008), while attractive scents of other taxa, such as

Wittko Francke recently passed away.

Florian Etl

florian.etl@univie.ac.at

Stefan Dötterl

stefan.doetterl@plus.ac.at

1 Department of Botany and Biodiversity Research, University of Vienna, Vienna, Austria

2 Institute of Organic Chemistry, University of Hamburg, Hamburg, Germany

3 Department of Environment \& Biodiversity, Paris Lodron University of Salzburg, Salzburg, Austria gall midges (Cecidomyiidae), have not yet been identified, despite knowing that olfactory cues are often key attractants (e.g., Gardner et al. 2018).

Plants mainly pollinated or co-pollinated by gall midges occur in various lineages, such as Schisandraceae (e.g., Illicium spp.), Malvaceae (e.g., Theobroma cacao), and Araceae (Young 1985, 1986, Luo et al. 2010; Schwerdtfeger et al. 2002). In Araceae, several species of Anthurium are pollinated by these insects (Schwerdtfeger et al. 2002). The plants often attract high numbers of midges, and it was hypothesized that floral scents guided the midges to the inflorescences of these plants. However, floral scents have not been studied for any gall midge pollinated Anthurium species so far, and it is currently unclear how these interacting organisms communicate.

During recent observations of Anthurium acutangulum Engl. at the "La Gamba Tropical Research Station" in Costa Rica, we observed that inflorescences are frequently visited by gall midges at night. Here, we describe the pollination biology of A. acutangulum, and elucidate the chemical communication between this plant species and its gall midge pollinators. Specifically, we asked: 1) What are the main characteristics of the process of anthesis and the pollination 
biology of A. acutangulum? 2) Which floral scent compounds are released by the inflorescences? 3) Are the main compounds attractive to the midges?

\section{Methods and Materials}

\section{Plant Material and Study Site}

Anthurium acutangulum (Araceae; sect. Porphyrochitonium) occurs from Panama to Honduras in wet tropical forests, from sea level up to $900 \mathrm{~m}$ asl. It is an epiphyte that frequently grows on the trunks of small understory trees. The flowers are hermaphroditic, protogynous, and arranged in several spirals around a spike, called a spadix (Fig. 1). The study was carried out on five individual plants between February and September of five successive years (2015-2019) at the edge of the Piedras Blancas National Park, in and near the La Gamba Tropical Research Station, Costa Rica $\left(08^{\circ} 42^{\prime} 02^{\prime \prime} \mathrm{N}, 83^{\circ} 12^{\prime} 07^{\prime \prime} \mathrm{W}\right)$. Vouchers of the plant species are deposited at the herbarium of the University of Vienna, Austria (WU).

\section{Anthesis, Floral Morphology, Fruiting}

Floral morphology during female and male phase and timing of anthesis were studied in all five individuals on one inflorescence each. Therefore, inflorescences were observed daily, starting prior to the beginning of anthesis, in the morning, in the evening, and at night to check for flower opening. Female and male sexual phases were determined by either the presence of moist stigmas or open anthers. Post-anthetic inflorescences were checked two weeks after anthesis for pollination success, i.e. if inflorescences were aborted or if fruits had started to develop (indicated by enlarged carpels).

\section{Scent Collection and Analyses}

Using dynamic headspace methods, we collected scents from four male and one female stage inflorescence $(\mathrm{N}=5$ individuals) of $A$. acutangulum during night-time (11:00 PM to 3:30 AM), when plants were strongly scented to the human nose and attracted high numbers of gall midges. Inflorescences were bagged with a polyethylene oven bag $(10 \times 30$ $\mathrm{cm}$; Toppits, Germany) and the scent was trapped for 2-3 min directly after bagging on an adsorbent tube (quartz glass tube: length $25 \mathrm{~mm}$; inner diameter $2 \mathrm{~mm}$ ) filled with $1.5 \mathrm{mg}$ each of Carbotrap B (mesh 20-40, Supelco, Germany) and Tenax TA (mesh 60-80; Supelco, Germany). For scent collection, a membrane pump (Gardner Denver, Germany) was used, and the flow was set at $200 \mathrm{ml} / \mathrm{min}$. To obtain negative controls, we conducted the same procedure, but with empty oven bags ( $\mathrm{N}=5$; see also Etl et al. 2016). Samples were stored in a freezer $\left(-20^{\circ} \mathrm{C}\right)$ and were analyzed ca. two weeks later with a GC/MS (coupled gas chromatograph/mass spectrometer; QP2010Ultra, Shimadzu Corporation, Japan) coupled to a thermal desorption unit (TD-20, Shimadzu, Japan) and equipped with a ZB-5 fused silica column (5\% phenyl polydimethylsiloxane; $60 \mathrm{~m}$ long, inner diameter $0.25 \mathrm{~mm}$, film thickness $0.25 \mu \mathrm{m}$, Phenomenex, USA). Samples were desorbed at $250{ }^{\circ} \mathrm{C}$ for $15 \mathrm{~min}$ (flow: $25 \mathrm{ml} / \mathrm{min}$ ) and cryofocused on a cold trap at $-20{ }^{\circ} \mathrm{C}$ in the TD-20, before they were transferred to the $\mathrm{GC}$ (cold trap heated to $250{ }^{\circ} \mathrm{C}$, transfer line from TD-20 to GC set to $260^{\circ} \mathrm{C}$ ). Samples were run at a column flow (carrier gas: helium) of $1.5 \mathrm{ml} / \mathrm{min}$. GC oven temperature started at $40{ }^{\circ} \mathrm{C}$, then increased by $6{ }^{\circ} \mathrm{C}$ per min to $250{ }^{\circ} \mathrm{C}$, and was held for $1 \mathrm{~min}$. The MS interface was set at $260^{\circ} \mathrm{C}$, and the ion source at $200{ }^{\circ} \mathrm{C}$. Mass spectra were taken at $70 \mathrm{eV}$ (in EI mode) from $\mathrm{m} / \mathrm{z}, 30$ to 350 . The GC/MS data were processed using GCMSolution Version 4.11 software (Shimadzu Corporation, Japan). Compounds were tentatively identified by matches with the NIST 11 , Wiley 9, FFNSC 2, Essential Oils, and Robert P. Adams 2007 mass spectral data bases, and were confirmed by comparison of mass spectra and retention times with those of authentic standards available in the stock collections of WF and SD. To determine the amount of scent in the samples, known amounts of monoterpenes, aliphatics, and aromatics were injected into the GC/MS system; mean peak areas of these compounds were used to determine the total amount of scent (see Dötterl et al. 2012).

To obtain a sample for enantioselective analyses of trans-conophthorin, scent was collected from a male stage inflorescence of $A$. acutangulum for three hours on a larger adsorbent tube, filled with $15 \mathrm{mg}$ each of the two different adsorbent materials. The trapped compounds were eluted with $1 \mathrm{~mL}$ acetone (pro analysi, Merck, Germany). Aliquots of $1 \mu \mathrm{L}$ of this sample, as well as of $(5 S, 7 S)$-trans-conophthorin and $(5 R, 7 R)$-trans-conophthorin (both available in the stock collection of WF) were injected, following Brandt et al. (2019), at a temperature of $250{ }^{\circ} \mathrm{C}$ into an Agilent 7890A gas chromatograph (Santa Clara, California, USA) equipped with a fused silica capillary column $(30 \mathrm{~m} \times 0.23$ $\mathrm{mm}$ i.d.), coated with a $0.23 \mu \mathrm{m}$ film of $0.4 \%$ heptakis(2,3di-O-methyl-6-O-tert-butyldimethylsilyl)-beta-cyclodextrin (DIME-beta-CD) (30\%) in SE-52 (70 \%). The GC oven temperature increased from $40{ }^{\circ} \mathrm{C}$ to $200{ }^{\circ} \mathrm{C}$ at a rate of 20 ${ }^{\circ} \mathrm{C}$ per minute.

\section{Observation of Floral Visitors}

The same five inflorescences of A. acutangulum as used for the analyses described above were observed for 15 min every two-hours for several days during both day and night during the female and male phases. All insects that visited the inflorescences were recorded and a subset of specimens were 
Fig. 1 Inflorescence, course of anthesis, and pollinators of Anthurium acutangulum. A) Flowering habit of A. acutangulum with a purple spadix and a greenish spathe (arrowhead). B) Detail of a female phase inflorescence with tightly packed flowers having moist and receptive stigmas (arrowhead); the stigma is surrounded by pink distal parts of the pistils; stamens are not visible during the female phase and each gynoecium is surrounded by four tepals (t). c, d) Male phase inflorescence with flowers having open anthers, visible by their yellow pollen; several gall midge individuals (Cecidomyiidae: Cecidomyiinae) are feeding on pollen. E) Gall midge with numerous pollen grains of $A$. acutangulum on its head, thorax, and legs (arrowheads). F) Numerous individuals of the gall midge pollinators that were attracted to a filter paper containing synthetic $(E 2, Z 6)$ 2,6-nonadienal during three hours of trapping using a BGSentinel trap. 1a,f) scale bar $=$ $1 \mathrm{~cm}, 1 \mathrm{~b}-\mathrm{e}$ ) scale bar $=1 \mathrm{~mm}$.
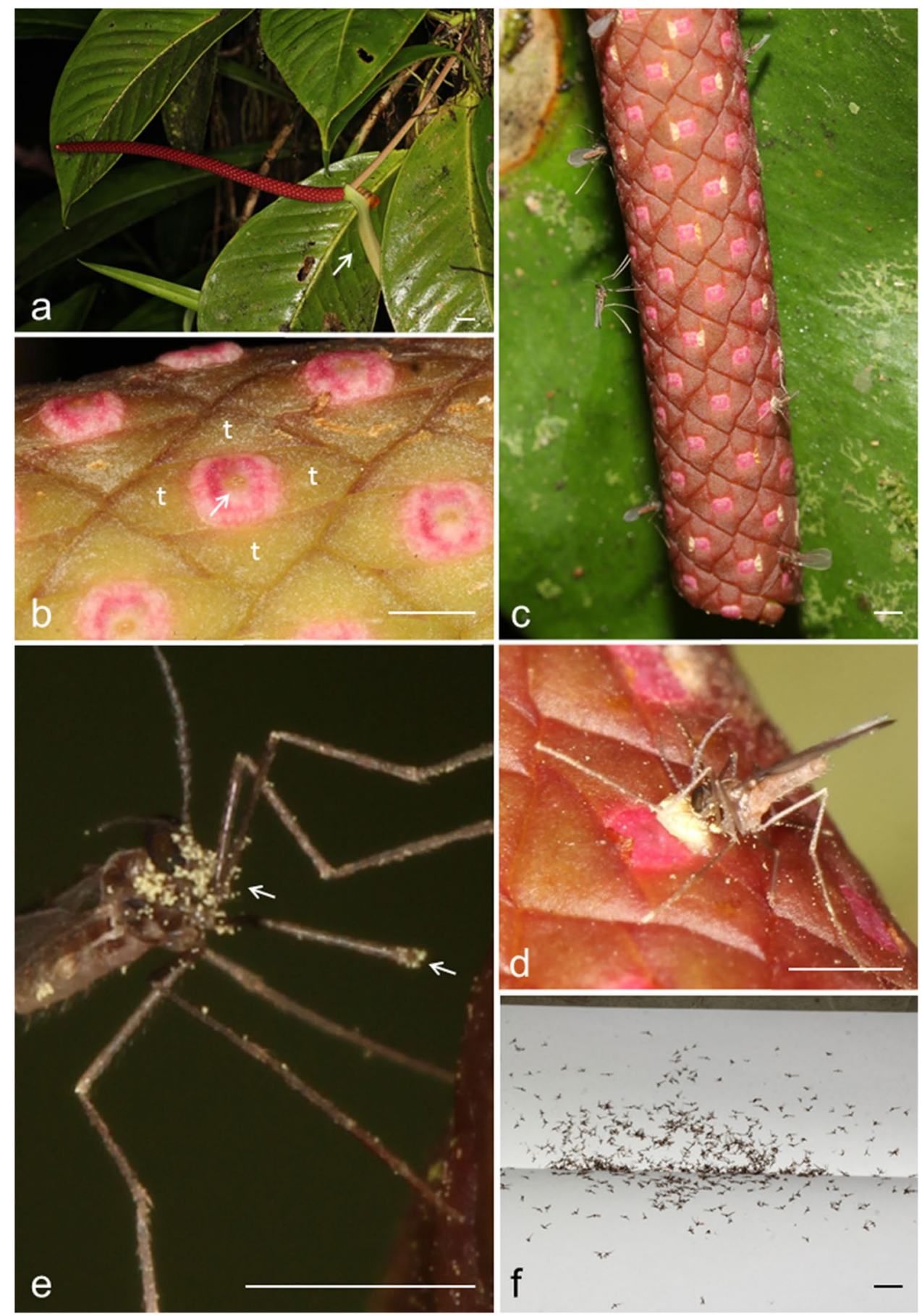

captured with an insect-aspirator to look for pollen on their bodies and for later identification. Vouchers of the insect species are deposited at the University of Vienna, Austria.

\section{Bioassays}

We tested synthetic (E2,Z6)-2,6-nonadienal (Sigma Aldrich, $\mathrm{USA} \geq 96 \% ; \mathrm{N}=5)$ and $(5 S, 7 S)$-trans-conophthorin $(\mathrm{N}=2)$, both main compounds in the scent of $A$. acutangulum (see
Results) in two-choice bioassays against negative controls (empty filter paper). (E2,Z6)-2,6-nonadienal was also tested against $(5 S, 7 S)$-trans-conophthorin $(\mathrm{N}=2)$ as well as a racemate of trans-conophthorin $(\mathrm{N}=2)$. Further, a mixture of (E2,Z6)-2,6-nonadienal and (5S,7S)-trans-conophthorin was tested against $(E 2, Z 6)-2,6$-nonadienal $(\mathrm{N}=2)$ and against a negative control $(\mathrm{N}=2)$. Pure compounds ( $200 \mu \mathrm{L}$ each) were tested in order to obtain emission rates comparable to that of a single inflorescence of the plant (see also Dötterl 
et al. 2012; Etl et al. 2016). Bioassays were performed within the flowering period of $A$. acutangulum in the study population, started at 9:00 PM, and lasted until 9:30 PM $(\mathrm{N}=13)$ or until midnight ( $N=2$, see details below). In our experiments, where we tested (E2,Z6)-2,6-nonadienal against negative controls, arriving insects were either collected with an insect-aspirator and the use of a head torch every 5 min over a period of $30 \min (\mathrm{N}=3)$ or were constantly trapped by BG-Sentinel traps (Biogents, Germany) that were placed 5 $\mathrm{cm}$ below the filter papers $(\mathrm{N}=2)$ for a period of $3 \mathrm{hr}$. As the arriving midges were easily scared away by light and BGSentinel traps were not available for further assays, for all other experiments we used a camera, equipped with infrared light (Sony HDR-PJ780), and counted the midges that were gathering on and around $(10-20 \mathrm{~cm})$ the filter papers every $10 \mathrm{~min}$ over a period of $30 \mathrm{~min}$ without catching them. With this method, we could not exclude counting the same individuals more than once within the three counts, and so we calculated mean values for the three counts of each of the ten experiments (see also Fig. 2 for more details). The (mean) numbers of insects attracted in the replicates of a specific two-choice assay were pooled for exact binominal tests of goodness-of-fit (http://www.biostathandbook.com/exact bin.xls) that compared the (mean) number of gall midges attracted by different lures.

\section{Results}

\section{Anthesis and Floral Morphology}

Flowering individuals of $A$. acutangulum were found in both the dry (January - March) and the rainy (July, August) seasons. Inflorescences consist of a dark red (Fig. 1a), sometimes more yellowish spadix, which is enclosed by a green spathe during development. The numerous, ca. $3 \mathrm{~mm}$ small flowers, which consist of a pistil surrounded by four conically shaped tepals, are tightly packed around the spadix. During anthesis, the spadix reaches a length of $15-20 \mathrm{~cm}$, a diameter of $1.5 \mathrm{~cm}$ at its base and $1 \mathrm{~cm}$ at its tip (Fig. 1a).

The female phase starts when the yellowish stigmas of almost all flowers synchronically open along the spadix. Receptivity is indicated by the wet appearance of the stigmas (Fig. 1b). Each night, from around 9:00 PM (ca. $3 \mathrm{hr}$ after nightfall), until sunrise (5:00 AM), the spadix continuously emitted a strong scent. This female phase with nocturnal scent production lasted 4-6 days, after which the stigmas wilted.

Around $24 \mathrm{hr}$ after wilting of the stigmas, the male phase started, i.e., the first anthers emerged from the surface of the spadix and released pollen (Fig. 1d). Within the following 12-14 nights, individual flowers started their male phase in an apparently random pattern along the spadix, with only
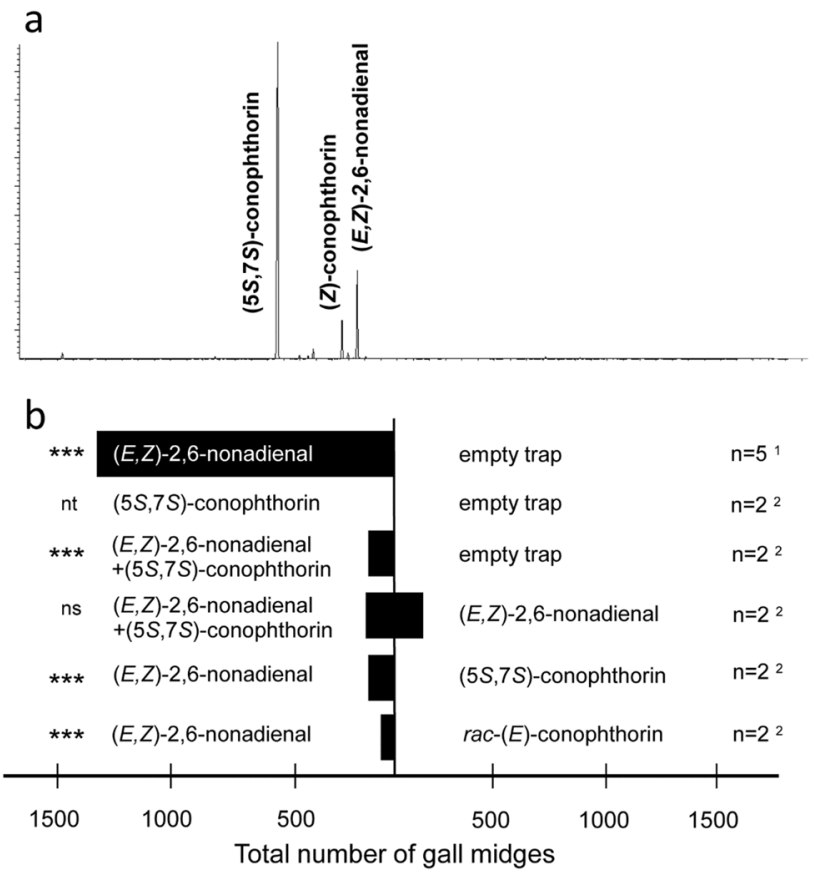

Fig. 2 a GC/MS chromatogram (total ion current) of a scent sample taken from a male phase inflorescence of Anthurium acutangulum at night. The sample is dominated by $(5 S, 7 S)$-trans-conophthorin, (E2,Z6)-2,6-nonadienal, and cis-conophthorin, and contained several other compounds in minor quantities (see Table S1); $\mathbf{b}$ results of a series of two-choice field bioassays, testing the activity of synthetic (E2,Z6)-2,6-nonadienal and (5S,7S)-trans-conophthorin alone, each against negative controls, against each other, and against a combination of both compounds as well as against synthetic racemic transconophthorin. ${ }^{1}$ : All individuals attracted during the choice assay were trapped for $30 \mathrm{~min}(\mathrm{n}=3)$ or a duration of $3 \mathrm{hr}(\mathrm{n}=2) .^{2}$ : Values give the mean number of attracted individuals of gall midges at three specific time points during $30 \mathrm{~min}$ experiments (see Methods and Materials for more details). Exact binomial tests: $* * *: P \leq 0.001$; ns: not significant; nt: not tested

one of the four anthers of a given flower opening per night. During each night a strong scent emission was perceived, similar to that of the female phase.

Two of the five inflorescences observed for fruiting aborted the spadix about two weeks after the end of anthesis. The other three inflorescences developed into infructescences with pink berries that were eaten by males of the orange collared manakin [Manacus aurantiacus (Salvin, 1870)].

\section{Floral Scent}

The floral scent of A. acutangulum was reminiscent of a freshly cut cucumber. We detected between $0.3 \mu \mathrm{g}$ and $8 \mu \mathrm{g}$ of scent and between three and 34 (overall 36) compounds in the samples (Table S1). Most of the compounds occurred only in small amounts, and only three compounds constituted more than $5 \%$ to the total scent discharge in at least one 
sample: $(5 S, 7 S)$-trans-conophthorin $(77 \%, 62 \%-98 \%$; mean, min-max), (E2,Z6)-2,6-nonadienal (10\%, 0-24\%), and cisconophthorin (7\%, 2-13\%) (Fig. 2a).

\section{Floral Visitors}

During the female and male phases (in total ca. three weeks), numerous (up to 20 at the same time and a total of on average 33 within an hour) female gall midges of a single morphotype (Cecidomyiidae, Cecidomyiinae) visited the inflorescences at night from ca. 9:00 PM until 5:00 AM (Fig. 1c). The midges landed on the spadix and, while directing their head to the surface of the spadix/flowers (Fig. 1d), crawled along the spadix from flower to flower, feeding on stigmatic exudates of the female phase and on pollen of the male phase inflorescences (Video S1). While feeding on male phase flowers, they became heavily loaded with pollen (Fig. 1e). Each midge spent at least a minute crawling up and down the spadix. The midges were also observed hanging from silky threads of unknown origin nearby the inflorescences, from where they kept flying back and forth to the spadix (Video S1).

Other visitors, which were rare, included one individual of another morphotype of gall midge, several individuals of ants patrolling on the inflorescences, two katydid (bush cricket) nymphs, and a predatory land-flatworm (Plathelminthes: Geoplanidae) that attacked and fed on the gall midge pollinators (Fig. S1).

\section{Bioassays}

In total, more than one thousand female midges of the same morphotype as the ones found on the plants were attracted by (E2,Z6)-2,6-nonadienal alone (Figs. 1f, 2b), and by a mixture of (E2,Z6)-2,6-nonadienal + (5S,7S)-transconophthorin when each was tested against a negative control (Fig. 2b). No midge responded to the negative controls and no midges were attracted when testing $(5 S, 7 S)$-transconophthorin alone against a negative control. When testing (E2,Z6)-2,6-nonadienal against $(5 S, 7 S)$-trans-conophthorin and against racemic trans-conophthorin, midges only responded to (E2,Z6)-2,6-nonadienal. Also, this compound alone attracted approximately the same number of midges as a mixture of $(E 2, Z 6)-2,6$-nonadienal $+(5 S, 7 S)$-transconophthorin (Fig. 2b). No insects other than the female gall midges were attracted during the bioassays.

\section{Discussion}

Our study showed that inflorescences of Anthurium acutangulum release a strong cucumber-like scent at night and are highly attractive to female gall midge pollinators at this period of the day. The spiroacetal $(5 S, 7 S)$-trans-conophthorin and (E2,Z6)-2,6-nonadienal were overall the most abundant compounds of the floral scent blend, of which (E2,Z6)-2,6-nonadienal resembled the scent of freshly cut cucumbers. Field bioassays revealed that (E2,Z6)-2,6-nonadienal attracted high numbers of the gall midge pollinators, whereas $(5 S, 7 S)$-trans-conophthorin was not attractive.

Based on the fact that the inflorescences of A. acutangulum were almost exclusively visited by a specific morphotype of gall midge, which visited female phase inflorescences, touching the receptive stigmas, and getting loaded with pollen while visiting male phase inflorescences (Fig. 1e), we classify these midges as the only effective pollinators of the studied plant population. Thus, we add $A$. acutangulum to the list of Anthurium species pollinated by this group of insects (Schwerdtfeger et al. 2002). In contrast to other species in this genus, $A$. acutangulum is visited by gall midges only at night and not during both day and night. Also, we did not observe the midges ovipositing into the flowers, a behavior known from other plants pollinated by gall midges, such as Artocarpus heterophyllus (jackfruit, Moraceae; Gardner et al. 2018) and Schisandraceae species (Luo et al. 2010).

The scent released by the inflorescences of $A$. acutangulum is highly specific and we are not aware of another plant species that releases a scent dominated by $(5 S, 7 S)$ trans-conophthorin (together with cis-conophthorin) and (E2,Z6)-2,6-nonadienal (Knudsen et al. 2006). It strongly differs from the scent released from inflorescences of Artocarpus heterophyllus, the only other plant where gall midges have been shown to respond to olfactory floral cues (Gardner et al. 2018). The scent of this Moraceae species is dominated by methyl 2-methylbutyrate, methyl isovalerate, and methyl tiglate, compounds that are not released by $A$. acutang $u$ lum. It obviously also differs from other Anthurium species that are pollinated by gall midges because these species are described as having flowers that are scentless to the human nose (Schwerdtfeger et al. 2002). Interestingly, however, a cucumber-like floral scent is emitted by Liparis viridiflora (Kaiser 1993). Flowers of this orchid release mainly $(E, E)-\alpha-$ farnesene, a compound not detected in samples of $A$. acutangulum, but also conophthorin and (E2,Z6)-2,6-nonadienal. Species of Liparis are pollinated by small Diptera, among them potentially gall midges. The shared occurrence of these compounds in A. acutangulum and L. viridiflora might suggest convergent evolution in response to gall midge pollination. This, however, would imply that both compounds elicit responses from gall midges. However, in our study only (E2,Z6)-2,6-nonadienal attracted the gall midge pollinators, and it remains to be tested whether conophthorin is attractive to other gall midge species at other locations. That is, the large amount of floral scent released by $A$. acutangulum might be explained if it is competing with other 
sympatric species that also attract the same pollinator species at other sites.

To conclude, we have described a new specialized and mutualistic gall midge pollination system with pollen and stigmatic exudates as floral rewards (see also Yukawa et al. $2011)$. Also, we provide evidence that (E2,Z6)-2,6-nonadienal, a compound otherwise rare among floral scents (Knudsen et al. 2006) and not previously known to be involved in the chemical ecology of gall midges (Francke 2013; Hall et al. 2012), was highly efficient in attracting its female gall midge pollinators. It awaits determination in future studies whether this chemical is the only floral scent compound of $A$. acutangulum involved in the attraction of its pollinators, or if other compounds such as cis-conophthorin might be active as well. Also, it would be interesting to know whether $(5 S, 7 S)$-trans-conophthorin, the most abundant compound in the floral scent blend of A. acutangulum, has a function other than attraction of pollinators from distance, such as eliciting feeding behaviors in the gall midges, or repelling other potential flower visitors (e.g., florivores).

Supplementary Information The online version contains supplementary material available at https://doi.org/10.1007/s10886-022-01349-3.

Acknowledgements We thank Mathias Jaschhof for help with the identification of gall midges and for providing literature on gall midge pollination, Martin Streinzer for help with identification of the landflatworm as well as Mike Grayum for help with the identification of the plant species. We also thank Alexander Kainz, Dennis Kollarits, and Maria Lindhuber for assistance in the field, and Roman Fuchs, Robert Gittenberger, and Irmgard Schäffler for assistance in the laboratory. Further, we thank two anonymous reviewers for their helpful comments on an earlier version of the manuscript. For logistic support, we thank Werner Huber, Anton Weissenhofer, Daniel Schaber, and the staff of the La Gamba Tropical Research Station. For assistance with research permits in Costa Rica, we are grateful to Lourdes Vargas Fallas, Paula Mena Corea, and Javier Guevara Sequeira (SINAC). Research permissions INV-ACOSA-006-17 and INV-ACOSA-004-19 were kindly granted by (SINAC) - Sistema Nacional de Areas de Conservación de Costa Rica of the Ministry of Environment and Energy (MINAE). F.E. was supported by a KWA scholarship from the University of Vienna and additionally by a scholarship from the Verein zur Förderung der Tropenstation La Gamba.

Funding Open access funding provided by Paris Lodron University of Salzburg. F.E. was supported by a KWA scholarship from the University of Vienna and additionally by a scholarship from the Verein zur Förderung der Tropenstation La Gamba

Availability of Data and Material All data are included in the manuscript

Code Availability Not applicable

\section{Declarations}

Conflicts of Interest/Competing Interests The authors have no relevant financial or non-financial interests to disclose.

Open Access This article is licensed under a Creative Commons Attribution 4.0 International License, which permits use, sharing, adaptation, distribution and reproduction in any medium or format, as long as you give appropriate credit to the original author(s) and the source, provide a link to the Creative Commons licence, and indicate if changes were made. The images or other third party material in this article are included in the article's Creative Commons licence, unless indicated otherwise in a credit line to the material. If material is not included in the article's Creative Commons licence and your intended use is not permitted by statutory regulation or exceeds the permitted use, you will need to obtain permission directly from the copyright holder. To view a copy of this licence, visit http://creativecommons.org/licenses/by/4.0/.

\section{References}

Brandt K, Dötterl S, Fuchs R, Navarro DMDF, Machado ICS, Dobler D, Reiser O, Ayasse M, Milet-Pinheiro P (2019) Subtle chemical variations with strong ecological significance: stereoselective responses of male orchid bees to stereoisomers of carvone epoxide. J Chem Ecol 45:464-473. https://doi.org/10.1007/ s10886-019-01072-6

Dötterl S, David A, Boland W, Silberbauer-Gottsberger I, Gottsberger G (2012) Evidence for behavioral attractiveness of methoxylated aromatics in a dynastid scarab beetle-pollinated Araceae. J Chem Ecol 38:1539-1543. https://doi.org/10.1007/s10886-012-0210-y

El-Sayed AM (2021) The Pherobase: database of insect pheromones and semiochemicals. http://www.pherobase.com

Etl F, Berger A, Weber A, Schönenberger J, Dötterl S (2016) Nocturnal plant bugs use cis-jasmone to locate inflorescences of an Araceae as feeding and mating site. J Chem Ecol 42:300-304. https://doi. org/10.1007/s10886-016-0688-9

Francke W (2013) Signalstoffe bei Insekten: strukturprinzipien und evolution. Entomologie heute 25:1-30

Gardner EM, Gagne RJ, Kendra PE, Montgomery WS, Raguso RA, McNeil TT, Zerega NJC (2018) A flower in fruit's clothing: pollination of Jackfruit (Artocarpus heterophyllus, Moraceae) by a new species of gall midge, Clinodiplosis ultracrepidata sp nov (Diptera: Cecidomyiidae). Int J Plant Sci 179:350-367. https:// doi.org/10.1086/697115

Hall DR, Amarawardana L, Cross JV, Francke W, Boddum T, Hillbur Y (2012) The chemical ecology of cecidomyiid midges (Diptera: Cecidomyiidae). J Chem Ecol 38:2-22. https://doi.org/10.1007/ s10886-011-0053-y

Kaiser R (1993) Vom duft der orchideen. Editiones Roche, Basel

Knudsen JT, Eriksson R, Gershenzon J, Ståhl B (2006) Diversity and distribution of floral scent. Bot Rev 72:1-120. https://doi.org/10. 1663/0006-8101(2006)72[1:DADOFS]2.0.CO;2

Luo SX, Chaw SM, Zhang DX, Renner SS (2010) Flower heating following anthesis and the evolution of gall midge pollination in Schisandraceae. Am J Bot 97:1220-1228. https://doi.org/10.3732/ ajb.1000077 
Raguso RA (2008) Wake up and smell the roses: the ecology and evolution of floral scent. Annu Rev Ecol Evol Syst 39:549-569. https:// doi.org/10.1146/annurev.ecolsys.38.091206.095601

Schwerdtfeger M, Gerlach G, Kaiser R (2002) Anthecology in the neotropical genus Anthurium (Araceae): a preliminary report. Selbyana 23:258-267

Young AM (1985) Studies of cecidomyiid midges (Diptera: Cecidomyiidae) as cocoa pollinators (Theobroma cacao L.) in Central America. Estudios de las mosquitas cecidómyiidas (Diptera: Cecidomyiidae) como polinizadoras del cacao (Theobroma cacao L.) en Centroamérica. Proc Entomol Soc Wash 87:49-79
Young AM (1986) Distribution and abundance of Diptera in flypaper traps at Theobroma cacao L. (Sterculiaceae) flowers in Costa Rican cacao plantations. J Kansas Entomol Soc 59:580-587

Yukawa J, Sato S, Xu H-1, Tokuda M (2011) Description of a new species of the genus Resseliella (Diptera: Cecidomyiidae), a pollinator of Kadsura longipedunculata (Schisandraceae) in China, with comments on its flower-visiting habit. Entomol Sci 14:297-303. https://doi.org/10.1111/j.1479-8298.2011.00446.x 